\title{
SOCIAL APPEARANCE ANXIETY OF FITNESS PARTICIPANTS
}

\author{
Serdar Alemdag, Ceyhun Alemdag, Abdullah Bora Ozkara \\ Karadeniz Technical University, Trabzon, Turkey
}

\begin{abstract}
Background. It is known that there are multiple associations between physical activity and psychology for human health. One of these associations is social appearance anxiety. Social appearance anxiety is a feeling of distress associated with the perceived evaluation of one's physical self. Some individuals feel relatively little anxiety over this perceived evaluation, while others are highly stressed. There are many studies on physical activity and anxiety, but fewer studies on the social appearance anxiety. Therefore, the aim of this research is determining social appearance anxiety of individuals interested in physical activity and examining it according to some variables.

Methods. The study group of the research consisted of 38 women (age $=28.53 \pm 9.1$ years), 190 men (age $=$ $26.43 \pm 7.78$ years) from four different fitness centres, with a total number of 228 individuals. The data were collected using Social Appearance Anxiety Scale as a data collection tool. Descriptive statistics, $t$ test for independent groups and one-way analysis of variance (ANOVA), Tukey's multiple comparison; Kruskal-Wallis $H$ test in the group not normally distributed were used as statistical methods for the evaluation of data.

Results. Adolescences and those aiming at losing weight demonstrated more social appearance anxiety compared to young adults and those aiming to keep fit.

Conclusion. It was determined that outgoing individuals demonstrated moderate levels of social appearance anxiety towards physical activity. Social appearance anxiety of individuals did not vary according to body mass index (BMI) and gender, but it varied in dependence age group and reasons for participating in physical activity. Thus it is said that the variables of age and reasons for participating in physical activity are determinant attributes of social appearance anxiety.
\end{abstract}

Keywords: exercise, fitness, anxiety.

\section{INTRODUCTION}

$\mathrm{T}$ he importance individuals attach to their appearance is a fact recognized all over the world. Therefore, they try a lot of ways to leave a more favourable impression on others and to look attractive, muscular or beautiful (Yousefi, Hassani, \& Shokri, 2009). Under the influence of TV shows, women wish to have a slimmer body while men desire to have a more muscular body.

In TV shows where thinness or attractiveness is represented as a cultural value, physical appearance may often take precedence over an individual's thoughts, behaviour or achievements (Cusumano \& Thompson, 1997). This leads individuals to wish for an ideal physique and to experience social appearance anxiety (Davison \& McCabe, 2005). Mc Candles suggests that social life is based on person's physical attributes and bodily attitudes and emphasizes the psychological importance of body image (Özerkan, 2004).

Theoretical foundations of social appearance anxiety show that individuals seek to create a positive impression in the eyes of others, and it has been suggested that social appearance anxiety appears when individuals feel incapable of presenting a desired image to others (Hagger \& Stevenson, 2010). Body mass index (BMI) most likely appears to be positively related to appearance-based social anxiety (Titchener \& Wong, 2015). Studies have 
shown a positive association between BMI and appearance-based social anxiety in female-only or predominantly female samples (Crocker, Sabiston, Kowalski, McDonough, \& Kowalski, 2006; Diehl, Johnson, Rogers, \& Petrie, 1998; Levinson et al., 2013). Furthermore, some studies have failed to find the BMI and appearance-based social anxiety association (Levinson \& Rodebaugh, 2011).

Social appearance anxiety is a concept that has been recently investigated by researchers in association with participation in sports (Berry \& Howe, 2004; Brunet \& Sabiston, 2009; Dumciene, Gedviliene, \& Mickevicius, 2015; Eriksson, Baigi, Marklund, \& Lindgren, 2008; Haase, Prapavessis, $\&$ Owens, 2002). Studies conducted in exercise psychology have clearly highlighted the positive effects of regular participation in physical activity on physical and psychological health (Aşç1, 2002; Dishman \& Jackson, 2000; Fox, 1997; Paluska \& Schwenk, 2000). Particularly studies focusing on the effect of physical exercise on a set of psychological variables have indicated that regular participation in physical activity may have a direct positive effect on such psychological variables as depression (Dimeo, Bauer, Varahram, Proest, \& Halter, 2001; Tilindienè, Emeljanovas \& Hraski, 2014; McKercher et al., 2009; Mikkelsen et al., 2010; Ströhle, 2009), anxiety (Tarakci, Yeldan, Mutlu, Baydogan, \& Kasapcopur, 2011; Martinsen, 2008), stress (Salmon, 2001), self-esteem (Fox, 2000), social self-efficacy (Alemdağ, 2013), body image (Hausenblas \& Fallon, 2006) and happiness (Özkara, Kalkavan, \& Cavdar, 2015) in normal samples.

As seen above, it is possible to find studies on the appearance anxiety of individuals who participate in physical activity. However, there is no study that investigates the reasons for participation in sports and body mass index of individuals interested in fitness along with their appearance anxiety. Thus, the present study aims to identify the perceptions of individuals interested in fitness sports toward appearance anxiety and to compare their perceptions with respect to gender, age, body mass index and reasons for their interest in fitness sports.

\section{METHODS}

Participants. The study group of the research consisted of 38 women $(\bar{x}$ (age) $=28.53 \pm 9.1$ years), 190 men $(\bar{x}$ (age $)=26.43 \pm 7.78$ years $)$ from four different fitness centres, with a total number of 228 individuals who completed a questionnaire package that included Social Appearance Anxiety Scale and some demographic information. The sample group was just randomly selected from a fitness centre, so women's sample size was extremely lower than men's because men generally prefer such sports centres a lot in many parts of Turkey.

Procedures. This research used a questionnaire as data collection method. The questionnaire is a commonly utilized data collection tool in quantitative research (F. C. Nachmias \& D. Nachmias, 1996). The questionnaires were distributed after obtaining the necessary permits from fitness centres' managers. The participation in the survey was voluntary.

Instrument. Personal Information Form. The Personal Information Form consisted of five questions related to the independent variables studied in the present research. These were as follows: gender, age, height, weight and the reason for going to the fitness centre (lose weight, keep fit, muscle mass, estc.) In this study, age categories were defined as follows: adolescents, $12-19$ years; young adults, 20-34 years; and middle adults, 35-50 years, because most people who used fitness centres usually were in these age groups. Additionally, height and weight measurements were taken using standard protocol (height with a portable stadiometre, weight with portable electronic scales and without shoes) and then BMI (body mass index) was calculated using that data. Finally, research team asked all participants about the reasons for exercising and then they had to sign their answers on the questionnaire. Soon all the information except for height and weight was collected using a questionnaire.

Social Appearance Anxiety Scale (SAAS). The Social Appearance Anxiety Scale (Hart et al., 2008) is a 16-item assessment of anxiety about being negatively evaluated by others because of one's overall appearance, including body shape. Items are rated on an agreement scale from not at all (1) to extremely (5). Research on the psychometric properties of the SAAS demonstrated high testretest reliability, good internal consistency, good factor validity, incremental validity (e.g., it was a unique predictor of social anxiety above and beyond negative body image indicators), and divergent validity in samples of nonclinical college men and women (Hart et al., 2008; Levinson \& Rodebaugh, 2011). Internal consistency reliability in the present study was excellent for women (coefficient alpha $=$ .97 ) and men (coefficient alpha $=.96$ ). 
Statistical analysis. The data were collected using Social Appearance Anxiety Scale and personal information form as a data collection tool. Independent simple $t$ test was used to assess differences between social appearance anxiety and gender, one-way ANOVA was used to access age differences, and Kruskal-Wallis $H$ test in the group not normally distributed was used as a statistical method for the evaluation of data. The analysis was conducted using SPSS (Version20). A p-value of $<$ .05 was used as the criterion for significance

\section{RESULTS}

Independent simple $t$ test was conducted to test whether there were significant differences according to gender in the SAAS points.

Analysis showed that there were no significant differences between social appearance anxiety and gender of participants $\left(t_{(226)}=-1.19, p>.05\right)$ (Table 1).

One way ANOVA was conducted to test whether there were significant differences according to age in the SAAS points. Analysis showed that there were significant differences between social appearance anxiety and age of participants $\left(F_{(2,225)}=\right.$
$3.62, \mathrm{p}<.05)$. In other words, social appearance anxiety of participants was different depending on their age. According to the result of the Tukey's HSD test which was performed to determine which groups made differences between age groups, social appearance anxiety of the participants in the 12-19 age group $(\bar{x}=2.02)$ was determined to be higher than the social appearance anxiety of the participants in the 20-34 age group ( $\bar{x}=1.75$ ).

BMI of the participants, Kruskal-Wallis $H$ test results taken from the SAAS scores are presesnted in Table 3. Analysis show that there is no significant differences between social appearance anxiety and BMI of participants.

Kruskal-Wallis $H$ test results taken from the SAAS scores of participants who came to the gym for different reasons are given in Table 4. Analysis showed that there were significant differences between social appearance anxiety and causes of participants go to the gym $\left(\chi^{2}(s d=3, n=228)=\right.$ $14.44, p<.05)$. This finding indicates that the reason to go to the gym shows different effects on the social appearance anxiety of the participants. Considering the average numbers of groups, apparently the highest concern seems to be with those who went to the gym to lose weight.
Table 1. Distribution of the SAAS points by gender

Notes. $p>.05$, SAAS - Social Appearance Anxiety Scale.

Table 2. Distribution of the SAAS points by age

Notes. $* p<.05$, SAAS Social Appearance Anxie-ty Scale.

Table 3. The distribution of the SAAS points by BMI

Notes. $p>.05$, SAAS - Social Appearance Anxiety Scale.

\begin{tabular}{|c|l|c|c|c|c|c|c|}
\hline \multirow{3}{*}{ SAAS } & \multicolumn{1}{|c|}{ Gender } & $\boldsymbol{n}$ & $\bar{x}$ & $\boldsymbol{S s}$ & $\boldsymbol{s} \boldsymbol{d}$ & $\boldsymbol{t}$ & $\boldsymbol{p}$ \\
\cline { 2 - 8 } & Women & 38 & 1.70 & 0.69 & \multirow{2}{*}{226} & -1.19 & .24 \\
\cline { 2 - 9 } & Men & 190 & 1.84 & 0.65 & & & \\
\hline
\end{tabular}

\begin{tabular}{|c|c|c|c|c|c|c|c|c|}
\hline \multirow{4}{*}{$\begin{array}{c}\text { SAAS } \\
\text { (points) }\end{array}$} & Age & $\boldsymbol{n}$ & $\bar{x}$ & $\boldsymbol{S s}$ & $\boldsymbol{s} \boldsymbol{d}$ & $\boldsymbol{F}$ & $\boldsymbol{p}$ & Sig. Dif. \\
\cline { 2 - 9 } & $(1) 12-19$ & 53 & 2.02 & 0.68 & & & & \\
\cline { 2 - 10 } & $(2) 20-34$ & 138 & 1.75 & 0.61 & $2-225$ & 3.62 & $.03 *$ & $1-2$ \\
\cline { 2 - 9 } & $(3) 35-50$ & 37 & 1.77 & 0.73 & & & & \\
\hline
\end{tabular}

\begin{tabular}{|c|l|c|c|c|c|c|}
\hline \multirow{4}{*}{$\begin{array}{c}\text { SAAS } \\
\text { (points) }\end{array}$} & \multicolumn{1}{|c|}{ Groups } & $\boldsymbol{n}$ & Mean rank & $\boldsymbol{\chi}^{2}$ & sd & $\boldsymbol{p}$ \\
\cline { 2 - 5 } & Low weight & 7 & 118.50 & & & \\
\cline { 2 - 5 } & Normal & 127 & 110.24 & & & \\
\cline { 2 - 5 } & High weight & 75 & 118.05 & \multirow{2}{*}{6.872} & \multirow{2}{*}{4} & .14 \\
\cline { 2 - 5 } & Obesity-1 & 15 & 109.43 & & & \\
\cline { 2 - 5 } & Obesity-2 & 4 & 195.25 & & & \\
\hline
\end{tabular}




\begin{tabular}{|c|c|c|c|c|c|c|c|}
\hline \multirow{5}{*}{$\begin{array}{c}\text { SAAS } \\
\text { (points) }\end{array}$} & Groups & $n$ & Mean rank & $\chi^{2}$ & $s d$ & $p$ & Sig. Dif. \\
\hline & (1) Lose weight & 41 & 136.61 & \multirow{4}{*}{14.442} & \multirow{4}{*}{3} & \multirow{4}{*}{$.00 *$} & \multirow{4}{*}{$1-2$} \\
\hline & (2) Keep fit & 109 & 100.47 & & & & \\
\hline & (3) Muscle mass & 63 & 129.52 & & & & \\
\hline & (4) Other & 15 & 92.93 & & & & \\
\hline
\end{tabular}

Table 4. Distribution of the SAAS points by the reason of attending the fitness centre

Notes. $p<.01$, SAAS Social Appearance Anxiety Scale.

\section{DISCUSSION}

This study conducted to examine social appearance anxiety of individuals participating in physical activity established that males had higher levels of social appearance anxiety than females but there was no significant difference between social appearance anxiety of males and females. This result is in parallel with those of the study conducted by Altintas and Asci (2005). Dogan (2009) also reported that men had higher levels of social appearance anxiety than women. The present study has also similar results to the study by Alemdag and Oncu (2015) on preservice teacher's participation in physical activity and social appearance anxiety. There may be a number of reasons behind such results. For instance, men are socially expected to undertake more initiatives, and fear and avoidance behaviours that arise due to social anxiety cannot be attributed to the male identity. Therefore, men may have higher social anxiety. However, Villiers (2009) reported that men had lower social anxiety than women. Such dissimilarity between the result of the present study and that of Villiers may be based on national differences in culture and gender relations. Western people are more relaxed communicating with each other easily and this is one type of culture for them, but Turkish society imposes more responsibility to men, thus men usually should be more sociable in Turkey if they wish to communicate with someone. Tha is why possibility of social appearance anxiety on men in Turkey is higher than that in women, and this is an expected result.

Based on the study results, there was a significant difference between Social Appearance Anxiety Scale (SAAS) scores of individuals participating in physical activity in terms of age variable. This difference was visible in the mean SAAS scores of individuals in the age group of 12-19 years participating in physical activity and those in the age group of 20-34 years. This result is similar to that of the study conducted by Alemdag (2013) on university students. Previous research also lends support to this similarity (Schneier, Johnson, Hornig, Liebowitz, \& Weissman, 1992; Kessler, Berglund, Demler, Jin, \& Walters, 2005). Alemdağ (2013) indicated that students in the age group of 17-19 years had the highest mean score of social appearance anxiety. This may result from the fact that individuals in the age group of 17-19 years still bear the traces of adolescence and have not yet completed their cognitive processes.

In the present study, no significant difference was found between SAAS scores and BMI of individuals participating in physical activity. This result is in parallel with the study by Örsel, Canpolat, Akdemir, \& Özbay (2004). This result suggests that social appearance anxiety results from the discrepancy between the perceived and ideal body (Gruber, Pope, Lalonde, \& Hudson, 2001; Ogden \& Evans, 1996).

The study results revealed a significant difference between individuals participating in physical activity for different reasons (losing weight, keeping fit, looking muscular and others) in terms of their social appearance anxiety. The difference was observed between individuals participating in physical activity for losing weight and those participating in physical activity for keeping fit. Recent research also lends support to this result (Fox, 2000; Krane, Waldron, Stiles-Shipley, \& Michalenok, 2001). Given that individuals participating in physical activity for losing weight are currently fat, it is an expected result that these individuals have high social appearance anxiety. Accordingly, it is a normal result that individuals participating in physical activity for keeping fit have low social appearance anxiety since they are currently fit. There are studies on the reasons for participation in physical activity (Kolt, Driver, \& Giles, 2004; Jakobsson, Lundvall, \& Redelius, 2014; Allender, Cowburn, \& Foster, 2006) while the literature lacks a study that discusses these reasons with social appearance anxiety. Thus, the present study is believed to contribute to the literature in this area. 


\section{CONCLUSION}

All in all, it seems that positive changes occur in the levels of social appearance anxiety of individuals participating in physical activity. On the one hand, physical activity leads to a change in the physical appearance of individuals; on the other hand, this change enables individuals to enhance their self-esteem and to have positive thoughts about the self. As it is clearly apparent that participation in physical activity has numerous benefits to individuals, our most important task is to tell people the importance of physical activity and to set up areas and projects that attract them to physical activity. Moreover, in order to better understand the impact of physical activity on these concepts, such variables as a larger sample group, the role of the parent on sport, the economic condition of the parent and the availability of sports facilities in their neighbourhood should be discussed in future studies.

\section{REFERENCES}

Alemdag, S. (2013). Investigating participation in physical activity, perceived social self-efficacy and social self-image among university students (Doctoral dissertation). Educational Sciences Institute, Karadeniz Technical University. Retrieved from https://tez.yok. gov.tr/UlusalTezMerkezi/tezSorguSonucYeni.jsp

Alemdağ, S., \& Öncü, E. (2015). The investigation of participation in physical activity and social appearance anxiety for the preservice teachers. International Journal of Science, Culture and Sport (IntJSCS), 3(3), 287-300.

Allender, S., Cowburn, G., \& Foster, C. (2006). Understanding participation in sport and physical activity among children and adults: A review of qualitative studies. Health Education Research, 21(6), 826-835. doi: 10.1093/her/cyl063

Altıntaş, A., \&Aşçı, F. H. (2005). Body related perception of fitness instructors. Spormetre Beden Ĕgitimi ve Spor Bilimleri Dergisi, 3(3), 101-104.

Aşçı, F. H. (2002). The effects of step dance on physical self perception of female and male university students. International Journal of Sport Psychology, 33, 431-442.

Berry, T. R., \& Howe, B. L. (2004). Effects of healthbased and appearance-based exercise advertising on exercise attitudes, social physique anxiety and selfpresentation in an exercise setting. Social Behavior and Personality: An International Journal, 32(1), 1-12.

Brunet, J., \& Sabiston, C. M. (2009). Social physique anxiety and physical activity: A self-determination theory perspective. Psychology of Sport and Exercise, 10(3), 329-335. doi: 10.1016/j.psychsport.2008.11.002

Crocker, P. R. E., Sabiston, C. M., Kowalski, K. C., McDonough, M.H., \& Kowalski, N. (2006). Longitudinal assessment of the relationship between physical selfconcept and health-related behavior and emotion in adolescent girls. Journal of Applied Sport Psychology, 18, 185-200. doi: 10.1080/10413200600830257

Cusumano, D. L., \& Thompson, J. K. (1997). Body image and body shape ideals in magazines: Exposure, awareness, and internalization. Sex roles, 37(9), 701-721.

Davison, T. E., \& McCabe, M. P. (2005). Relationships between men's and women's body image and their psychological, social, and sexual functioning. Sex roles, 52(7-8), 463-475.

Diehl, N. S., Johnson, C. E., Rogers, R. L., \& Petrie, T. A. (1998). Social physique anxiety and disordered eating: What's the connection. Addictive Behaviors, 23, 1-6.

Dimeo, F., Bauer, M., Varahram, I., Proest, G., \& Halter, U. (2001). Benefits from aerobic exercise in patients with major depression: A pilot study. British Journal of Sports Medicine, 35, 114-117. doi:10.1136/ bjsm.35.2.114

Dishman, R. K, \& Jackson, E. M. (2000). Exercise, fitness and stress. International Journal of Sport Psychology, 31, 175-203.

Doğan, T. (2009). Investigation of cognitive and self-evaluation processing in terms of social anxiety (Unpublished doctoral dissertation). Sakarya University, Social Sciences Institue, Sakarya. Retrieved from https://tez.yok.gov. tr/UlusalTezMerkezi/tezSorguSonucYeni.jsp.

Dumciene, A., Gedviliene, J., \& Mickevicius, V. (2015). Relationship between women's body dissatisfaction, sense of coherence and physical activity. Baltic Journal of Sport and Health Sciences, 96(1), 9-15.

Eriksson, L., Baigi, A., Marklund, B., \& Lindgren, E. C. (2008). Social physique anxiety and sociocultural attitudes toward appearance impact on orthorexia test in fitness participants. Scandinavian Journal of Medicine \& Science in Sports, 18(3), 389-394. doi: 10.1111/j.16000838.2007.00723.x

Fox, K. R. (2000). Exercise, self esteem and self perceptions. In Physical Activity and Psychological Well Being (pp. 88-118). London and New York: Routledge.

Fox, K. R. (1997). The physical self and processes in self esteem development In K. R. Fox (Ed.), The physical self: From Motivation to Well Being (pp. 111-141). Champaign, IL: Human Kinetics.

Gruber, A. J., Pope, Jr, H. G., Lalonde, J. K., \& Hudson, J. I. (2001). Why do young women diet? The roles of body fat, body perception, and body ideal. Journal of Clinical Psychiatry, 62(8), 609-611.

Haase, A. M., Prapavessis, H., \& Owens, R. G. (2002). Perfectionism, social physique anxiety and disordered 
eating: A comparison of male and female elite athletes. Psychology of Sport and Exercise, 3(3), 209-222. doi: 10.1016/S1469-0292(01)00018-8

Hagger, M. S., \& Stevenson, A. (2010). Social physique anxiety and physical self-esteem: Gender and age effects. Psychology \& Health, 25(1), 89-110. doi: 10.1080/08870440903160990

Hart, T. A., Flora, D. B., Palyo, S. A., Fresco, D. M., Holle, C., \& Heimberg, R. G. (2008). Development and examination of the social appearance anxiety scale. Assessment, 15(1), 48-59. doi: $10.1177 / 1073191107306673$

Hausenblas, H. A \& Fallon, E. A. (2006). Exercise and body image: A meta-analysis. Psychology \& Health, 21(1) 33-47. doi: 10.1080/14768320500105270

Jakobsson, B. T., Lundvall, S., \& Redelius, K. (2014). Reasons to stay in club sport according to 19-year-old Swedish participants: A salutogenic approach. Sport Science Review, 23(5-6), 205-224. doi: 10.1515/ssr2015-0002

Kessler, R. C., Berglund, P., Demler, O., Jin, R., \& Walters, E. E. (2005). Life time prevalence and age of onset distributions of DSM-IV disorders in the national comorbidity survey replication. Archives in General Psychiatry, 62, 593-602. doi:10.1001/archpsyc.62.6.593 Kolt, G. S., Driver, R. P., \& Giles, L. C. (2004). Why older Australians participate in exercise and sport. Journal of Aging \& Physical Activity, 12(2), 185-198.

Krane, V., Waldron, J., Stiles-Shipley, J. A., \& Michalenok, J. (2001). Relationships among body satisfaction, social physique anxiety, and eating behaviors in female athletes and exercisers. Journal of Sport Behavior, 24(3), 247.

Levinson, C. A., Rodebaugh, T. L., White, E. K., Menatti, A. R., Weeks, J. W., \& Iacovino, J. M. (2013). Social appearance anxiety, perfectionism, and fear of negative evaluation. Distinct or shared risk factors for social anxiety and eating disorders? Appetite, 61, 125-133.

Levinson, C. A., \& Rodebaugh, T. L. (2011). Validation of the Social Appearance Anxiety Scale: Factor, convergent, and divergent validity. Assessment, 18(3), 350-356. doi: 10.1177/1073191111404808

Martinsen, E. W. (2008). Physical activity in the prevention and treatment of anxiety and depression. Nordic Journal of Psychiatry, 62, 25-29. doi: 10.1080/08039480802315640

McKercher, C. M., Schmidt, M. D., Sanderson, K. A., Patton, G. C., Dwyer, T., \& Venn, A. J. (2009). Physical activity and depression in young adults. American Journal of Preventive Medicine, 36(2), 161-164. doi: 10.1016/j.amepre.2008.09.036

Mikkelsen, S. S., Tolstrup, J. S., Flachs, E. M., Mortensen, E. L., Schnohr, P., \& Flensborg-Madsen, T. (2010). A cohort study of leisure time physical activity and depression. Preventive Medicine, 51(6), 471-475. doi: 10.1016/j.ypmed.2010.09.008

Nachmias, C. F \& Nachmias, D. (1996). Research Methods in the Social Sciences (5th ed.). London: Arnold. Ogden, J. E., \& Evans, C. (1996). The problem of weighing: Effects on body image, self esteem and mood. International Journal of Obesity, 20, 272-277.

Örsel, S., Canpolat, B. I., Akdemir, A. \& Özbay, H. (2004). Diyet yapan ve yapmayan ergenlerin kendililik algısı, beden imajı ve beden kitle indeksi açısından karşılaştırılması. Türk Psikiyatri Dergisi, 15(1), 5-15.

Ozkara, B. A., Kalkavan, A., \& Cavdar, S. (2015). examination of the life satisfactions levels of students receiving education in sports sciences. International Journal of Science Culture and Sport (IntJSCS), Special Issue (3), 336-346.

Özerkan, K. N. (2004). Spor psikolojisine giriş. Temel Kavramlar, Nobel Yayın Dağıtım (pp. 107-108). Ankara. Paluska, S. A., \& Schwenk, T. L. (2000). Physical activity and mental health. Sports Medicine, 29(3), 167180.

Salmon, P. (2001). Effects of physical exercise on anxiety, depression, and sensitivity to stress: A unifying theory. Clinical Psychology Review, 21(1), 33-61. doi: 10.1.1.454.814

Schneier, F. R., Johnson, J., Hornig, C. D., Liebowitz, M. R., \& Weissman, M. M. (1992). Social anxiety: Comorbidity and morbidity in an epidemiologic sample. Archives of General Psychiatry, 49, 282-288.

Ströhle, A. (2009). Physical activity, exercise, depression and anxiety disorders. Journal of Neural Transmission, 116(6), 777-784. doi: 10.1007/s00702-008-0092-x

Tarakci, E., Yeldan, I., Mutlu, E. K., Baydogan, S. N., \& Kasapcopur, O. (2011). The relationship between physical activity level, anxiety, depression, and functional ability in children and adolescents with juvenile idiopathic arthritis. Clinical Rheumatology, 30(11), 1415-1420.

Tilindienè, I., Emeljanovas, A., \& Hraski, M. (2014). Relationship between self-esteem, self-confidence and anxiety for adolescent athletes and non-athletes of Kaunas city. Baltic Journal of Sport and Health Sciences, 95(4), 50-56.

Titchener, K., \& Wong, Q. J. (2015). A weighty issue: Explaining the association between body mass index and appearance-based social anxiety. Eating Behaviours, 16, 13-16.

Villiers, D. P. (2009). Perfectionism and social anxiety among college students (Doctoral dissertation). Northeastern University.

Yousefi, B., Hassani, Z., \& Shokri, O. (2009). Reliability and factor validity of the 7-item social physique anxiety scale (SPAS-7) among university students in Iran. World Journal of Sport Sciences, 2(3), 201-204. 